УДК 781.7

DOI: https://doi.org/10.33643/kmus.2019.59.05

$$
\begin{array}{r}
\text { Уень Юньцзя, } \\
\text { аспирантка кафедры теории музыки } \\
\text { Национальной музыкальной академии Украины им. П. И. Чайковского } \\
\text { https://orcid.org/0000-0002-0362-7912 } \\
\text { chengyunjia@hotmail.com } \\
\text { Cheng Yunjia, } \\
\text { Postgraduate at the Theory of Music Department, } \\
\text { Ukrainian National Tchaikovsky Academy of Music } \\
\text { https://orcid.org/0000-0002-0362-7912 } \\
\text { chengyunjia@hotmail.com }
\end{array}
$$

\title{
ФАКТОР СИММЕТРИИ И ЕЕ ПРЕОДОЛЕНИЯ НА РАЗНЫХ УРОВНЯХ ЦЕЛОСТНОСТИ КАК ОСОБЕННОСТЬ КИТАЙСКОГО СИМФОНИЗМА (НА ПРИМЕРЕ УВЕРТЮРЫ «ТАНЕЦ НАРОДА ЯО» В РЕДАКЦИИ МАО ЮАНЯ)
}

Актуальность исследования заключается в отсутствии глубокого анализа произведения, несмотря на то, что оно являет собой прекрасный образец сочетания западных и восточных традиций. Цель заключается в анализе структурных особенностей, формирующих композиционнодраматургическую идею произведения Мао Юаня. Метод исследования: феноменологический, метод целостного анализа, структурный, системный и метод историзма. Bыbоды. Анализ симфонической увертюры «Танец народа Яо» показал глубинные связи симфонизма Мао Юаня с песнями и танцами народов Китая. Несмотря на использование традиционных европейских форм, их трактовка - китайская и воплощает разные символы: от Инь-Янь, до цикличности времён года.

Ключевые слова: танец, симфонизм, симметрия, символика, период, форма.

Yunjia Cheng. The structure symmetry and its overcoming as the feature of China's symphony (exemplified by the "Yao people dance» in Mao Yuan transcription). The relevance of the study. For this moment we do not have a fundamental analysis of this opus, despite the fact that it is a perfect and significance example of the conjunction Western composer technics and philosophy and mentality of Chinese people. The main objective of the study is analysis of the features of the harmony, themathism and texture, which form of the composition and dramaturgy Mao Yuan's work. Methodology. The main method of the research is phenomenological (because «Yao people dance» takes 
a unique place in Chinese music and is estimated as a phenomenon). Also, we used a complexity analysis (for describing form and texture of the work), historical (for describe the historical context of the "Yao people dance»), structure and system methods. They are used for the initial of the structural combination's factors and system parameters of the suite's genre.

Result/findings and conclusions. The analysis of the symphonic overture "Yao people dance» demonstrates the deep interaction of Mao Yuan's symphonic style with the songs and dances of the Chinese people. Despite the using of European forms and genres, their interpretation is absolutely Chinese on the mental level.

Firstly, we can see this on the inviolable structure of the periods. Every of such structure has an eight measure's structure and, for its inner logic, absolutely square. Therefore every this theme perceived as the axiom that doesn't require development. A theme might have been approved due to expansion on the orchestral texture's level (that we have seen in the A and B theme).

Moreover, both themes are created by Mao Yuan as perfect symmetry structures, which have been influenced by Chinese philosophy (particularly Yin and Yang).

Probably, «Yao people dance» is an example of perception of multi-level musical structure. The first level is the period with the eight measure's structure. The second level is a binary and three-part form . Third level is a complex twopart form as the structure of the A, B and C sections. Fourth level - three-part form, which organized composition and dramaturgy all this overture.

Significance. "Yao people dance» is representative of Chinese music around the world. So, in this research, we have improved the fact of an influential Chinese philosophy, instruments, folk to the European genres and forms.

Key words: dance, symphony, symmetry, symbols, period, the form.

Юньцзя Чень. Чинник структурної симетрії та її подолання як особливість китайського симфонізму (на прикладі «Танцю народу Яо» в транскрипції Мао Юаня). Актуальність дослідження. На цей момент ми не маємо фундаментального аналізу опусу «Танець народу Яо», незважаючи на те, що він $є$ показовим і значущим прикладом поєднання західної композиторської техніки 3 філософією та ментальністю китайського народу. Головною метою дослідження є аналіз особливостей гармонії, тематизму, фактури, форми композиції та драматургії твору Мао Юаня. Методологія. Основний метод дослідження - феноменологічний (оскільки «Танець народу Яо» посідає унікальне місце в китайській музиці і сприймається як іiї феномен). Також нами було використано метод цілісного аналізу (для опису форми та фактури твору), метод історизму (для опису 
історичного контексту «Танцю народу Яо»), структурний та системний методи. Вони використовуються для встановлення характеру структурної комбінації та системних параметрів жанру увертюри в межах твору.

Результат/Висновки. Аналіз симфонічної увертюри «Танець народу Яо» продемонстрував глибоку взаємодію симфонічного стилю Мао Юаня 3 піснями й танцями китайського народу. Незважаючи на використання європейських форм i жанрів, їx інтерпретація на ментальному рівні - абсолютно китайська.

По-перше, це виявилося у структурі періодів. Кожен із них має обсяг у вісім тактів і є абсолютно квадратним за своєю внутрішньою логікою. Тому кожна ця тема сприймається як аксіома, яка не потребує розвитку, $\mathrm{i}$ можливо, буде лише стверджена за рахунок розширення на рівні оркестрової фактури (що ми бачили в темах $A$ і $B$ ).

До того ж, в обох темах Мао Юань створив ідеальні структури симетрії, які випливають з китайської філософії (зокрема, Інь і Ян).

Швидше за все, «Танець народу Яо» $є$ прикладом багаторівневої музичної структури. Перший рівень - це період, що складається 3 восьмитактів. Другий рівень - це двочастинна та тричастинна форми. Третій рівень - це складна двочастина форма, як структура розділів $A, B$ i $C$. Четвертий рівень - тричастинна форма, в якій організована композиція і драматургія всієї увертюри.

Значення дослідження. «Танець народу Яо» є зразком китайської академічної музики, що представляє іiі у всьому світі. В цьому дослідженні ми встановили факт впливу китайської філософії, інструментів, фольклору на європейські жанри та форми.

Ключові слова: танець, симфонія, симетрія, символіка, період, форма.

Актуальность исследования. «Танец народа Яо» - одно из наиболее выдающихся произведений китайской академической музыки, известное далеко за пределами страны, в том числе и в Украине. В то же время, приходится констатировать отсутствие глубокого анализа данного произведения, несмотря на то, что оно являет собой прекрасный образец сочетания западных композиторских техник и структур с философскими идеями и мировоззрением, характерными для жителей Китая. На наш взгляд, анализ и понимание проявляющихся в «Танце народа Яо» смыслов станет важным звеном в раскрытии понимания симфонизма в творчестве и других композиторов Китая, что представляется актуальной и перспективной сферой для дальнейших научных поисков. 
Новизна предлагаемой статьи заключается, во-первых, в комплексном подходе к структурообразующим факторам, что позволит подчеркнуть уникальность произведения, а во-вторых - в оценке роли «Танца» в истории современной китайской академической музыки.

Цель статьи заключается в анализе гармонических, фактурных и тематических особенностей, формирующих композиционнодраматургическую идею произведения Мао Юаня. Цель определяет следующие задачи:

- определить контексты создания увертюры «Танец народа Яо»;

- исследовать жанровые черты увертюры и их реализацию в «Танце»;

- проанализировать композиционно-драматургическую идею увертюры;

- определить специфику уровней целостности произведения.

Метод исследования. В рамках данной статьи нами осуществляется попытка интегрировать традиционные европейские подходы к анализу формы с представлениями о музыке среди жителей Китая.

Касательно последних, очень яркой и убедительной представляется высказывание Цзя Ваньиня в статье «Исторический анализ музыкальной культуры Китая». В ней отмечается следующее: «Для жителей древнего Китая характерен взгляд на музыку, как на нечто всеохватывающее, как на своеобразный мир, построенный по образцу космического порядка. Ясные, высокие музыкальные звуки выражают небо, сильные и более низке по тональности - землю. Широкое распространение получили аналогии с явлениями природы в музыке: музыкальное произведение делится на четыре части, по аналогии четырёх времён года; круги, созданные в танцах, символизируют ветер и дождь; пять звуков гаммы составляют “чудесное целое" пяти цветов <...>. Пентатонный ряд соответствует пяти первоэлементам, порождающим гармонию» ${ }^{1}$ [3, с. 2]. Подобный подход к символике и аналогиям позволит выявить глубинные связи симфонического целого в рамках увертюры Мао Юаня.

В свою очередь, с европейской точки зрения, данное произведение выглядит весьма классическим. Особенно классический подход проявляется на уровне музыкальной формы, для которой характерны

\footnotetext{
1 «Для давніх китайців є характерним погляд на музику як на дещо всеохоплююче, як на своєрідний світ, побудований по зразку космосу. Ясні, високі музині звуки $є$ вираженням неба, сильні та більш низькі по тональності - землі. Широке розповсюдження отримали аналогії з явищами природи у музиці: музичний твір поділяється на чотири частини, за аналогом чотирьох пір року; кола, створені у танці символізують вітер та дощ, п'ять звуків гамми складають “чудове ціле” п'яти квітів $<. .>$. Пентатонний ряд китайської музики відповідає п’яти першоелементам, що породжують гармонію» [3, с. 2].
} 
равновесие и симметрия. Л. Кириллина отмечает, что «Классицизм как тип мышления выдвигает на первые роли такие принципы как строгая упорядоченность, уравновешенность и симметрия. Но классика немыслима без свободы и без парадоксальных решений. <..> Классическая музыка опиралась на ставшую к тому времени «бестелесной» поэзию и на опосредованные этикетом и ритуалом приземленные формы движения (танец, марш, процессия). Классическая музыка живет в границах между поэтической свободой, витающей в высоте, но помнящей о земном притяжении. И разумной размеренностью материального мира, знающей о возможности приобщения к возвышенным истинам [4, с. 62].

Как видим, стремление к симметрии, сочетаемое с парадоксальностью, характерно и для европейского классического стиля. Соответственно, крайне любопытным может быть исследование «Танца народа Яо» в соответствии с принятыми в европейской музыке второй половины XVIII века принципами, что лежит в основе методологии данного исследования.

Основным методом исследования можно считать феноменологический, поскольку именно с позиций феномена происходит оценка «Танца народа Яо». Кроме того, как вспомогательные методы, используются: целостный анализ (при описании формы и фактуры сочинения), метод историзма (при введении «Танца» в исторический контекст), а также структурный и системный методы для определения факторов структурообразования и системных признаков жанра сюиты в рамках данного произведения.

Pезультаты. Рассматриваемую в данной статье версию «Танца народа Яо» для европейского оркестра (в редакции Мао Юаня) можно считать своеобразной фантазией, вдохновлённой фольклором и обычаями народа Яо - этнической группы численностью свыше 2,6 млн. человек. Они обитают в южном Китае, в частности - в провинциях Гуанси, Хунань, Юньнань, Гуанчжоу, Гуйчжоу и Цзянси.

История «Танца народа Яо» отличается большим вниманием, со стороны исполнителей и слушателей. Так, ещё в 1950-1951 годах китайский композитор Лю Тешань, путешествуя по южным провинциям, услышал народные мелодии и танцы народа Яо в день их праздника. Затем на основе полученных впечатлений он создал произведение «Танец длинных барабанов народа Яо». Позднее другой китайский композитор Мао Юань берёт за основу темы из произведения Лю Тешаня и создаёт «Танец народа Яо» для инструментов европейского оркестра. Премьера сочинения состоялась в 1953 году. 
Позднее появились версии для духового оркестра, версия Пен Сювен для оркестра традиционных китайских инструментов (1962 год); версия Чжоу Хундэ для струнного квартета европейского состава. Наконец переложение для трёх гуджен (китайский инструмент, отдалённо напоминающий цимбалы). Все эти версии стали популярными не только в Китае, но и в других странах, в том числе и в Украине.

«Танец народа Яо» является одним из ранних примеров китайской симфонической музыки, в котором традиции западноевропейской формы сочетаются с такими характерными методами работы, как вариационность (метод развития тем), трехчастность и двухчастность (основа формы), а также симфонизм как метод развития композиционно-драматургической идеи.

В диссертации Ло Шии [5], посвящённой китайской музыке, история развития китайского симфонического произведения разделена на периоды: период зарождения (1840-1927), период формирования в условиях раскола (1927-1949), период расцвета (1949-1966), период спада (1966-1976), период возрождения (с 1976 до настоящего времени). Как видим, «Танец народа Яо» относится к периоду расцвета китайской симфонической музыки, находившейся, как и само государство, на заре Новой эры.

Рассмотрим подробнее композиционно-драматургическую идею произведения. Можно сказать, что она воплотила в себе не только традиции китайского высокого искусства, но и дух академической музыки Европы и Северной Америки первой половины XX века. Попытка уйти от четырёхчастного классико-романтического цикла к более камерным и малым размерам, воплотить фольклорные элементы, ритмические модели и мелодии - эти и другие особенности характеризовали творчество таких композиторов, как Игорь Стравинский, Джордж Гершвин.

На подобную тенденцию указывал Марк Арановский: «Крупномасштабной композиции традиционной симфонии противопоставлялись сжатые, лаконичные формы; громоздкому и стандартному составу оркестра - малые, индивидуализированные; структуре сонатно-симфонического цикла - разнообразные нетипичные формы, с непостоянным количеством частей, глобальным философским концепциям - скромные замыслы с уклоном в область чисто музыкальных проблем; симфоническому развитию - концертирование» [1, с. 55].

Мысль учёного можно применить и к симфонической основе «Танца народа Яо». И вот почему:

1. Можно констатировать фольклорную основу, ведь композитор вдохновлялся танцами народа Яо на празднике китайского Нового Года. 
Здесь также используются традиционные китайские инструменты, даже при европейском составе оркестра (например, ударные п ай го).

2. Камерность. Это произведение - одночастное; в составе оркестра небольшое количество струнных и парный состав духовых.

3. Элементы концертирования, когда эпизоды tutti чередуются с мелодиями у скрипок, флейт и кларнетов.

Симфоническая целостность «Танца народа Яо» основана на смешанной форме. С одной стороны, опора на традиционные «структуры тональной музыки» (термин М. Бонфельда), а также преобладание диатонических ладовых звукорядов обуславливает трёхчастность, как общий план, режиссирующий композицию и драматургию произведения.

С другой стороны, констатируем вариационное развитие двух начальных тем - медленной распевной (далее обозначается как $A$ ) и быстрой танцевальной (далее обозначается как $B$ ) - и их ладовый контраст с темой центрального раздела (далее обозначается как $C$ ). Кроме того, можно выделить большое количество мотивов, из которых состоят линии аккомпанемента.

Рассмотрим детальнее закономерности структурообразования «Танца народа Яо». Первые четыре такта увертюры представляют собой остинато на тонах $c$ и $g$. В условиях ладотональности c-moll можно говорить о своеобразной игре тоники и доминанты. Однако в контексте симфонической идеи «Танца» эта игра практически не ощущается. Мотивный ход указанными выше нотами, изложенный октавным унисоном у Viole и Violoncello, создаёт ощущение пустоты и, так сказать, простоты. Завершающий штрих к начальным тактам привносит pizzicato на тонике в партии контрабаса (см. Пример № 1).

Пример № 1

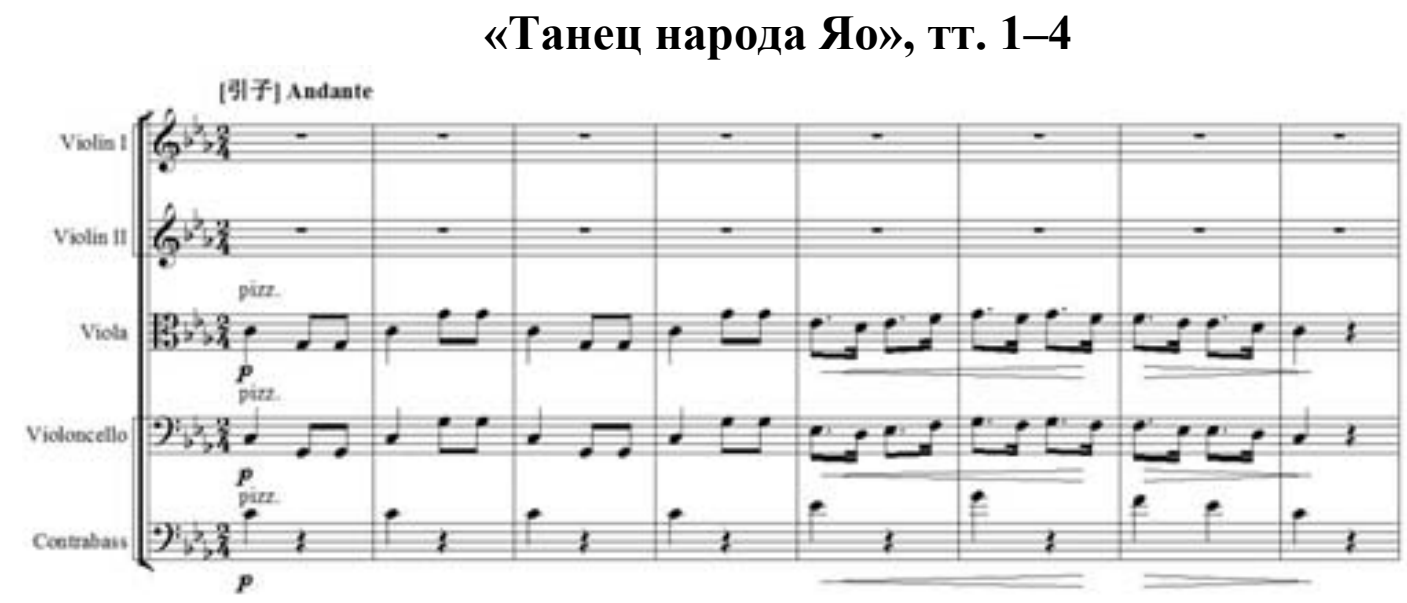

Подобная фактура сохраняется и в 5-8 тактах, однако с изменениями в мелодической линии. Вместо пустых, однообразных ходов - мелодия в пунктирном ритме. В таком виде происходит закругление данного вступления. 
Таким образом, Мао Юань использует структуру восьмитактового периода с логикой суммирования $(2+2+4)$. При этом с ладовой точки зрения он полностью диатоничен и натурален (без повышенной доминанты, к примеру). Можно сказать, он вполне сбалансирован и гармоничен, и это свидетельствует о том, что даже на таком уровне композитор стремился к равновесию в структуре и гармонии.

$\mathrm{C}$ девятого такта и обозначения литеры $A$ начинается изложение первой темы (см. Пример № 2). Мелодическая линия, исполняемая скрипкой на $p$ и dolce, основана на диатонических ладовых оборотах в пределах натурального $d$-moll. Её объем - также восемь тактов, которые объединены по логике периода квадратного строения $(2+2+2+2)$.

Пример № 2

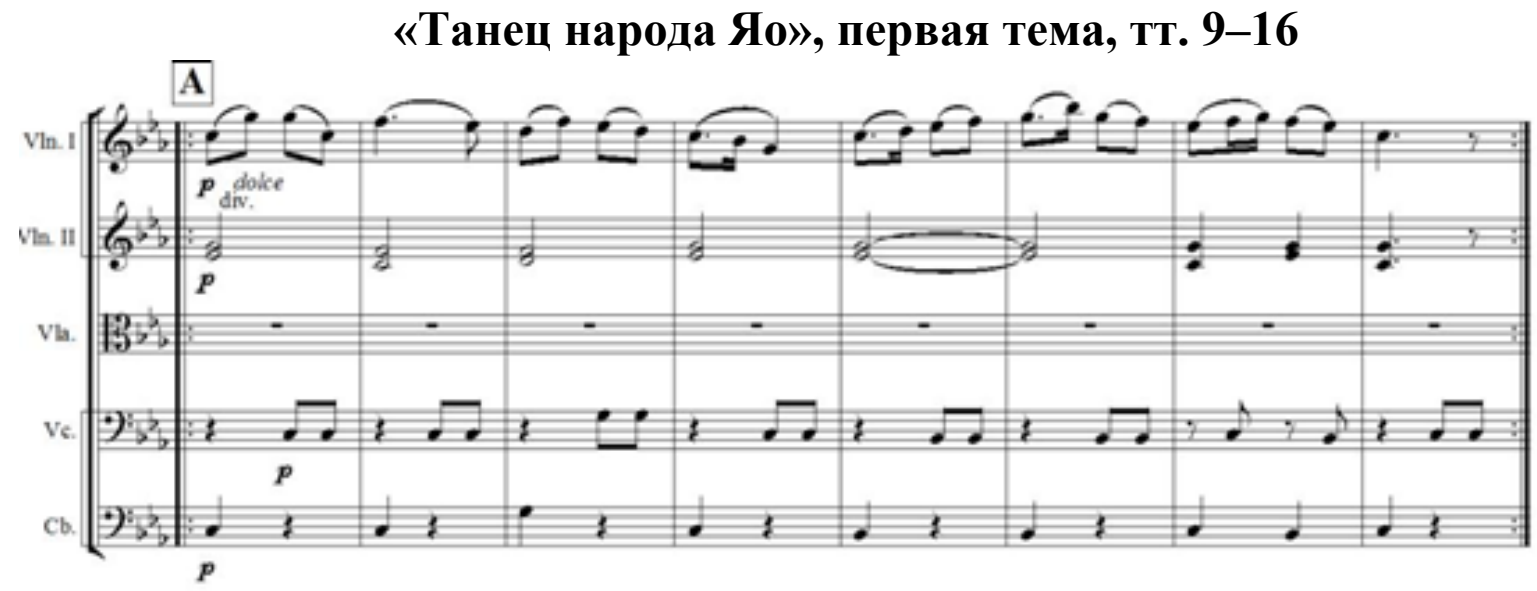

Отметим и тот факт, что остинато сохраняется. В партиях $V-c$ и $C-b$ можно видеть повтор ритма из 1-4 тактов, но с несколько иной конфигурацией нот. Также происходит вступление Oboe, играющего в унисон с партией второй скрипки. Таким образом, формируется трёхпластовая фактура, типа мелодия + гармония + бас. Полифоничность фактуры достигается минимальными средствами. На наш взгляд, можно констатировать тенденцию стремления к малой форме, о которой было сказано выше.

С 17 по 24 такты звучит своеобразный ответ разобранной выше теме. Почему его можно считать таковым? Прежде всего, из-за гармонических и мотивных особенностей. Если ранее преобладала мелодия с более простой ритмикой, на тонической (в большинстве случаев) гармонии, то сейчас - более взволнованная, устремленная вверх. Секвенционный повтор одного и того же мотива, в сочетании с дальнейшим уплотнением и расширением оркестровой фактуры, происходит в параллельном $E s-d u r$. Эти средства и создают ощущение ответа. Однако далее, в 21-24 тактах, происходит восстановление c-moll, а материал двух последних тактов совпадает с 15-16 тактами, в результате чего можно провести параллели с «рефреном» в народной мелодии. 
Таким образом, из темы (9-16 тт.) и ответа к ней (17-24 тт.) формируется целостность раздела $A$. Как видим, он изложен в простой двухчастной форме, где каждая из частей имеет структуру восьмитактового квадратного периода. Констатируем, что на данном уровне целостности композитор стремится к равновесию структур, с полным нивелированием противоречия в самом начале ответа.

В дальнейшем тема проводится ещё два раза. Композитор оставляет её неизменной на уровне гармонии и формы. Варьирование осуществляется лишь за счёт оркестровых средств: вступления новых инструментов и дивизий, дублирования и добавления новых подголосков (например, фигураций шестнадцатыми длительностями в партиях скрипок и альтов, начиная с 25-го такта. При третьем проведении происходит своеобразная рокировка: фигурации переходят к группе деревянных духовых), а тема - к струнным (исключая контрабас), где она звучит в унисон. Такие средства достаточно классичны, однако и в них прослеживается стремление композитора к структурному и гармоническому равновесию.

С 57-го такта начинается изложение новой темы (см. Пример № 3). Она полностью контрастна. Живой, энергичный танец, исполняемый в темпе Allegro фаготом в высоком регистре.

Пример № 3

«Танец народа Яо», вторая тема, тт. 57-64

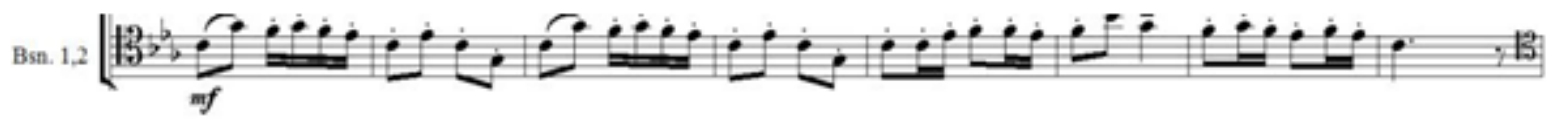

Более того, данная тема имеет и другое развитие, несмотря на структуры периода в её основе. Первые восемь тактов (57-64 тт.) основаны на двух равных предложениях (4+4), которые состоят из двух фраз каждая. Как видим - структура квадратная. За проведением темы следует восемь тактов наигрыша одного и того же мотива. Ещё далее - повтор темы. Таким образом, тема раздела $B$ излагается в простой трёхчастной форме $(8+8+8)$, со строго симметричными периодами.

Указанная тема проводится ещё раз. Её структура остаётся нерушимой, развитие осуществляется только за счёт расширения оркестра и уплотнения фактуры, т.е аналогично теме $A$. Во всём же остальном оба проведения полностью симметричны между собой.

Кроме того, симметрию можно наблюдать, если сравнить разделы $A$ и $B$ между собой. Так, раздел $A$ охватывает с 9 по 56-й такты, его объём равен 47 тактам. Раздел $B$ охватывает с 57 по 104-й такты, его объём также равен 47 тактам. Такое равенство лишь подтверждает желание композитора 
(возможно, неосознанное) реализовать идею симметрии не только на уровне периодов или отдельных тем, но и целых разделов увертюры.

После проведения темы $B$ начинается новый раздел $C$. По объёму он занимает 53 такта, со 114 по 167 тт. В нём отчётливо видно два раздела. Первый состоит из четырёх восьмитактовых периодов, причём второй и третий - один и тот же, дважды повторенный. Далее можно наблюдать тему у Cl-to соло, нежного и пасторального характера, в духе народных наигрышей (см. Пример № 4).

Пример № 4 «Танец народа Яо», пасторальная тема раздела $C$, TT. 139-146

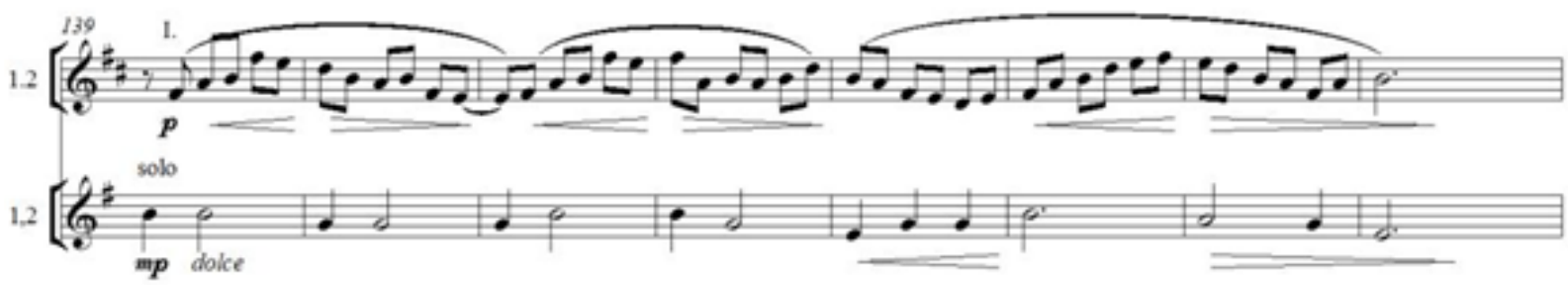

В этой теме можно наблюдать три периода и третий кульминационное проведение мелодии у струнных и деревянных духовых инструментов. Далее, после перехода, начинается реприза.

В репризе мы не наблюдаем симметричных построений на всех уровнях формы, за исключением периодов. Обе темы проводятся без изменений по одному разу. С 214 такта начинается кода, основанная на фрагменте из темы $A$, движение которого постепенно ускоряется и перерастает в новое качество - яркий, энергичный и праздничный танец.

В итоге, можно говорить о преодолении симметричных построений разделов $A, B$ и $C$ в пользу стихии праздничного танца, символизирующего радость людей от прихода китайского Нового Года.

Bbыводы. Таким образом, анализ симфонической увертюры «Танец народа Яо» показал глубинные связи симфонизма Мао Юаня с песнями и танцами народов Китая. Несмотря на использование традиционных европейских форм и жанров, их трактовка - глубоко китайская.

В первую очередь, это выражается в нерушимости темы-периода. Каждая из тем проводится как итог, как аксиома и не требует разработки. Она могла только утверждаться за счёт уплотнения в фактуре оркестра, что показала логика развития в темах $A$ и $B$. При этом, в обеих темах Мао Юаня выстроили образцовые симметричные конструкции, что по сути имеет глубинную связь с китайской философией (достаточно провести аналогию с Инь и Янь). 
Кроме того, «Танец народа Яо» - образец многоуровневого восприятия музыкальной конструкции и целостности:

1. Первый уровень целостности - восьмитактовый период.

2. Второй уровень целостности - простая двухчастная и трёхчастная формы (обнаруженные в темах $A$ и $B$ ).

3. Третий уровень целостности - сложная двухчастная форма как структура для разделов $A, B$ и $C$.

4. Четвертый уровень целостности - трёхчастная форма, организующая композиционно-драматургический план на высшем уровне.

Таким образом получается составная, но предельно ясная форма, как бы ощущается стремление автора к равновесию, балансу и гармонии во всех смыслах этого слова.

Отметим, также, что итоговая схема частей увертюры выглядит следующим образом: вступление $-A-B-C-A-$ кода. Исходя из приведённой выше цитаты Цзя Ваньинь [3], в этих четырёх разделах можно увидеть символ четырёх времён года, а также - цикличности в связи с репризным проведением раздела $A$.

«Танец народа Яо» стал представительным образцом китайской симфонической музыки во всём мире. Музыка сугубо китайская: основана на мотивах фольклора народа Яо, исполняется китайскими инструментами. В то же время, жанр и особенности формы построены по канонам европейского симфонизма.

1. Арановский М. Симфонические искания : монография. Ленинград : Советский композитор, 1979. $287 \mathrm{c}$.

2. Бонфельд М. Анализ музыкальных произведений : структуры тональной музыки : в 2 ч. Ч. 1. Москва : ВЛАДОС, 2003. 256 с.

3. Ваньїнь Цзя. Історичний аналіз музичної культури Китаю // Київське музикознавство : до 150-річчя Київського інституту музики ім. Р. М. Глієра. Вип. 55. Київ, 2017. URL: http://www.glierinstitute.org/ukr/digests/055/ (дата звернення: 27.03.2019).

4. Кириллина Л. Классический стиль в музыке XVIII - начала XIX века : в 3 томах. T. 2. Москва : Издательский дом «Композитор», 2007. 376 с.

5. Ло Шии. Симфонические жанры в контексте китайской музыкальной культуры : автореф. дисс. ... канд. искусствоведения : 17.00.02 / РАМ им. Гнесиных. Москва, 2003. $27 \mathrm{c}$.

6. Назайкинский Е. Логика музыкальной композиции : учеб. пособие. Москва : Музыка, 1982. 319 с.

7. Чулаки М. Инструменты симфонического оркестра : учеб. пособие. Москва : Музыка, 1972. 177 с.

8. Chengbei Xu. Peking Opera / transl. by Chen Gengtao. Beijing : China Intercontinental Press, 2003. 138 p. (Cultural China Series). 


\section{References}

1. Aranovskiy, M. (1979). Symphonic researches. Leningrad: Kompozitor [in Russian].

2. Bonfeld, M. (2003). The analysis of the music forms: the structures of the tonal music. Vol. 1. Moscow: VLADOS [in Russian].

3. Jia Wanning. (2017). Historical analysis of China's music culture. Kyivske muzykoznavstvo, 55. [online] Kyiv. Avaliable at: http://www.glierinstitute.org/ukr/ digests/055/ [in Ukrainian].

4. Kirillina, L. (2007). Classic style in music from the 18th - early 19th century. Part 2. Moscow: Kompozitor [in Russian].

5. Lo, Shii. (2003). The symphonic genres in the Chinese music culture's context. Extended abstract of $\mathrm{PhD}$ thesis. Moscow [in Russian].

6. Nazajkinskij, I. (1982). The logic of music composition. Moscow: Muzyka [in Russian].

7. Tchulaki, M. (1972). The instruments of the symphonic orchestra. Moscow: Muzyka [in Russian].

8. Chengbei, Xu. (2003). Peking Opera. Chen Gengtao (Trans.). Beijing: China Intercontinental Press [in English]. 